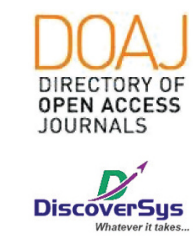

Published by DiscoverSys

\section{The correlation between serum magnesium level and blood pressure in patient with chronic kidney disease}

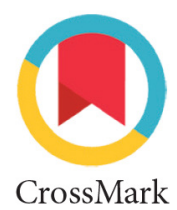

\author{
Maulida Devi Yanti ${ }^{*}$, Lisyani Budipradigdo Suromo²
}

\section{ABSTRACT}

Background: Increased blood pressure is one of the complications from hemodialysis in Chronic Kidney Disease (CKD) patients. Magnesium is an electrolyte which is a calcium antagonist in regulating blood pressure. This study aims to prove the correlation of serum magnesium level with blood pressure in CKD patients Methods: A cross-sectional study was conducted on 30CKD patients in Dr. Kariadi Hospital, Semarang during September-October 2018. The serum magnesium level was measured with spectrophotometry method, blood pressure with a sphygmomanometer. Statistical analysis used Pearson and Spearman correlation test.
Result: There is a significant correlation between serum magnesium level and systolic blood pressure with $p<0,001$ and $r=-0,737$ and correlation between serum magnesium level and diastolic blood pressure with $\mathrm{p}=0,011$ and $\mathrm{r}=-0,457$

Conclusion: There is a strong negative correlation of serum magnesium level with systolic blood pressure and moderate negative correlation of serum magnesium level with diastolic blood pressure in this study. Further studies are needed to analyze the influential factors of blood pressure.
${ }^{1}$ Clinical Pathology Resident of Faculty of Medicine of Diponegoro University, Semarang, Indonesia ${ }^{2}$ Clinical Pathology Department Staff of Faculty of Medicine of Diponegoro University, Semarang, Indonesia

* Corresponding to:

Maulida Devi Yanti; Clinical Pathology Resident of Faculty of Medicine of Diponegoro University, Semarang, Indonesia; maulidadeviyanti82@yahoo.com

Received : 2018-11-13 Accepted : 2019-03-11 Published : 2019-04-01

Keywords: CKD, Serum magnesium, Systolic blood pressure, Diastolic Cite This Article: Yanti, M.Y., Suromo, L.B. 2019. The correlation between serum magnesium level and blood pressure in patient with chronic kidney disease. Intisari Sains Medis 10 (1): 238-241. D0I: 10.1556/ism.v10i1.359

\section{INTRODUCTION}

Chronic Kidney Disease (CKD) is a disorder of the kidney characterized by structural abnormalities or a decrease in kidney function for more than three months. CKD is characterized by one or more signs of kidney damage such as albuminuria, urinary sediment abnormalities, electrolytes, histology, kidney structure, or the presence of a kidney transplant history, and accompanied by a decrease in glomerular filtration rate. At present, many studies show that the prevalence of CKD is increasing in various regions throughout the world. The prevalence of grade II to V of CKD has increased since 1988 following the increase in the prevalence of diabetes and hypertension which is also causing CKD. ${ }^{1,2}$

The data from 2011 showed that the causes of CKD were as follows, $14 \%$ Primary/GNC Glomerulopathy, 27\% Diabetic Nephropathy, 1\% Lupus Nephropathy/SLE, 34\% Hypertension Kidney Disease, 1\% Polycystic Kidney, 2\% Uric Acid Nephropathy, 8\% obstruction nephropathy, chronic pyelonephritis / PNC 6\%, and others 6\%, unknown $1 \%$. This is different from the world epidemiological data that places diabetic nephropathy as the most common cause of CKD. ${ }^{3}$

The Riskesdas in 2013 showed that the population aged $\geq 15$ years diagnosed with chronic kidney disease was $0.2 \%$. This figure is lower than the prevalence of CKD in other countries, as well as the results of the Indonesian Nephrology Association (PERNEFRI) study in 2006, which observed the prevalence of CKD for $12.5 \%$. This difference in the outcome between these studies may be caused by the data collection method. The Riskesdas only captured the data on people diagnosed with CKD, while most CKD in Indonesia was newly diagnosed at the later and final stages. The results of the 2013 Riskesdas also show that prevalence increases with age, with a sharp increase in the age group of 35-44 years compared to the age group of 25-34 years. The prevalence in men $(0.3 \%)$ is higher than women $(0.2 \%){ }^{4}$

Several factors can influence the occurrence of hypertension, some are unavoidable such as age and sex, but some can be prevented such as lack of magnesium, barium, calcium and potassium intake. Micronutrients that play a dominant role in the pathogenesis of essential hypertension are calcium and magnesium. A case-control study done by Putri (2014) showed that there was a relationship between magnesium and the incidence of hypertension. ${ }^{5}$

The Dietary Approaches to Stop Hypertension (DASH) has conducted various experiments which concluded that consuming high amounts of 
magnesium can reduce blood pressure. ${ }^{5}$ Magnesium has a vital role in efforts to control blood pressure by strengthening endothelial tissue, stimulating prostaglandins and increasing glucose capture so that insulin resistance can be reduced. If the concentration of magnesium in the blood decreases, the heart muscle cannot work optimally, affecting blood pressure. ${ }^{6}$ The research conducted by Lestari (2010) based on the results of bivariate tests did not find any association between magnesium intake and the incidence of hypertension. ${ }^{6}$

Magnesium $(\mathrm{Mg})$ is the second most commonly found intracellular cation after potassium. $\mathrm{Mg}$ is a potent inhibitor for smooth muscle vascular contractions and acts as a vasodilator in the regulation of blood pressure. Several studies have shown that magnesium deficiency will make arterial vasoconstriction and increase peripheral resistance which will increase the blood pressure. ${ }^{7,9}$,

Patients with a stage 5 of chronic kidney disease (CKD) undergoing dialysis, the serum magnesium depends on the concentration of dialysis solution. The decline of the kidney function significantly reduces the excretion capacity for magnesium. Several cohort studies state that hypomagnesemia can be used as a predictor of mortality and impairment of kidney function in CKD patients who are equal to the mortality of hemodialysis patients. ${ }^{10}$ Other study conducted by salamanja et al found that there are differences in the physical conditions and emotional reactions of patients with chronic kidney disease who underwent hemodialysis $\leq$ six months and $\geq$ six months. ${ }^{11,12}$ Based on the aforementioned above, this study aims to determine the correlation between serum magnesium level and blood pressure in patient with chronic kidney disease.

Table 1. Baseline characteristic of respondents

\begin{tabular}{lc}
\hline Characteristics & $\mathbf{N}=\mathbf{3 0}$ \\
\hline Age $($ Median $($ min. - max $)($ years $)$ & $39.5(35-35)$ \\
Magnesium level (Mean \pm SD) $(\mathrm{mg} / \mathrm{dL})$ & $0.84 \pm 0.10$ \\
Systolic Blood Pressure $($ Mean $\pm \mathrm{SD})(\mathrm{mmHg})$ & $152.17 \pm 12.37$ \\
Diastolic Blood Pressure $($ Median $($ min. - max $)(\mathrm{mmHg})$ & $87.5(80-100)$ \\
\hline
\end{tabular}

Table 2. Correlation test between Serum Magnesium and systolic and diastolic blood pressure

\begin{tabular}{ccc}
\hline \multicolumn{1}{c}{ Parameter } & \multicolumn{2}{c}{ Glomerular Filtration Rate } \\
& $\boldsymbol{p}$ & $\mathbf{r}$ \\
\hline Serum Mg and systolic blood pressure & $<0.001$ & $-0.737^{\star}$ \\
Serum Mg and diastolic blood pressure & 0.011 & $-0.457^{\star *}$ \\
\hline
\end{tabular}

* Pearson Correlation test

** Spearman Correlation test

\section{METHODS}

This is a cross sectional study conducted from September to October 2018 in Dr. Kariadi Hospital Semarang. Consecutive sampling was done with the target population of patients diagnosed with chronic kidney disease by an internist. The study involved 30 patients consisting of 20 men and ten women who fulfilled the inclusion criteria. The inclusion criteria were patient between the age of 35 to 45 years old, with a normal body temperature between $36.5^{\circ}-37.2{ }^{\circ} \mathrm{C}$, underwent hemodialysis for more than 6 months. The patient was excluded if the blood pressure cannot be measured using standard measurement procedure or patient who are vomiting during hemodialysis. Ethical clearance was obtained from the medical and health research ethics committee, Diponegoro University Medical School, Semarang.

The serum magnesium level was analyzed using the spectrophotometer method, while for the blood pressure measurements was using a sphygmomanometer.

The data obtained were analyzed using SPSS 15.0 for windows. All research data are displayed in the form of general characteristics (descriptive). The data normality was analyzed using Shapiro-Wilk test because the sample size is less than 50 , followed by an association test using the Pearson test if normally distributed, otherwise the Spearman's test will be used. The p-value is significant if $<0.05$ with a $95 \%$ confidence interval.

\section{RESULT}

Based on patient data on patients with chronic disease in RSUP Dr.Kariadi Semarang, collected during the period September - October 2018, a total of 30 subjects were included, consisting of 20 men and ten women. The characteristics of the research subject can be seen in table 1 .

The correlation test found a significant different between systolic and diastolic blood pressure to the serum magnesium level $(\mathrm{P}<0.05)$. In addition there is also a strong negative correlation between serum Mg and systolic blood pressure ( $\mathrm{r}:-0.737)$, but moderate negative correlation between serum $\mathrm{Mg}$ and diastolic blood pressure (r: -0.457) (Table 2; Figure 1 and 2)

\section{DISCUSSION}

The results showed that serum magnesium levels have a strong inverse correlation to systolic blood pressure. The mechanism of anti-hypertension in magnesium has been confirmed in previous laboratory studies. Magnesium plays a role in the pathogenesis of hypertension through the 


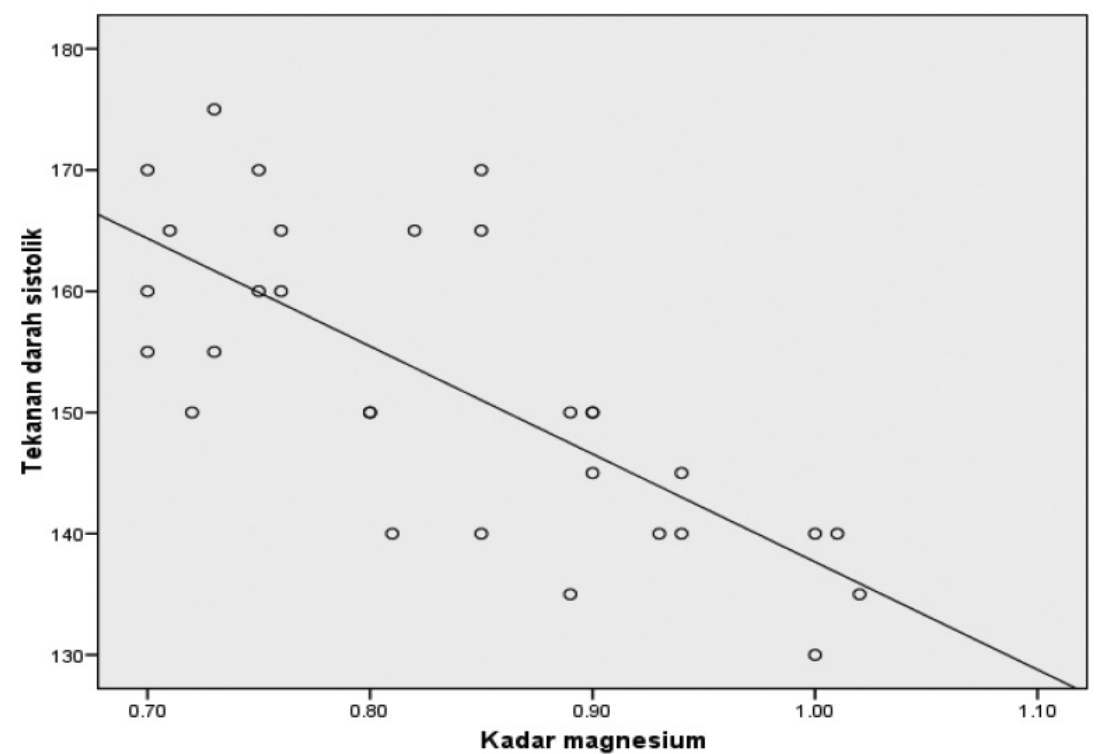

Figure 1. Scatter plot for correlation between blood serum Magnesium level and systolic blood pressure

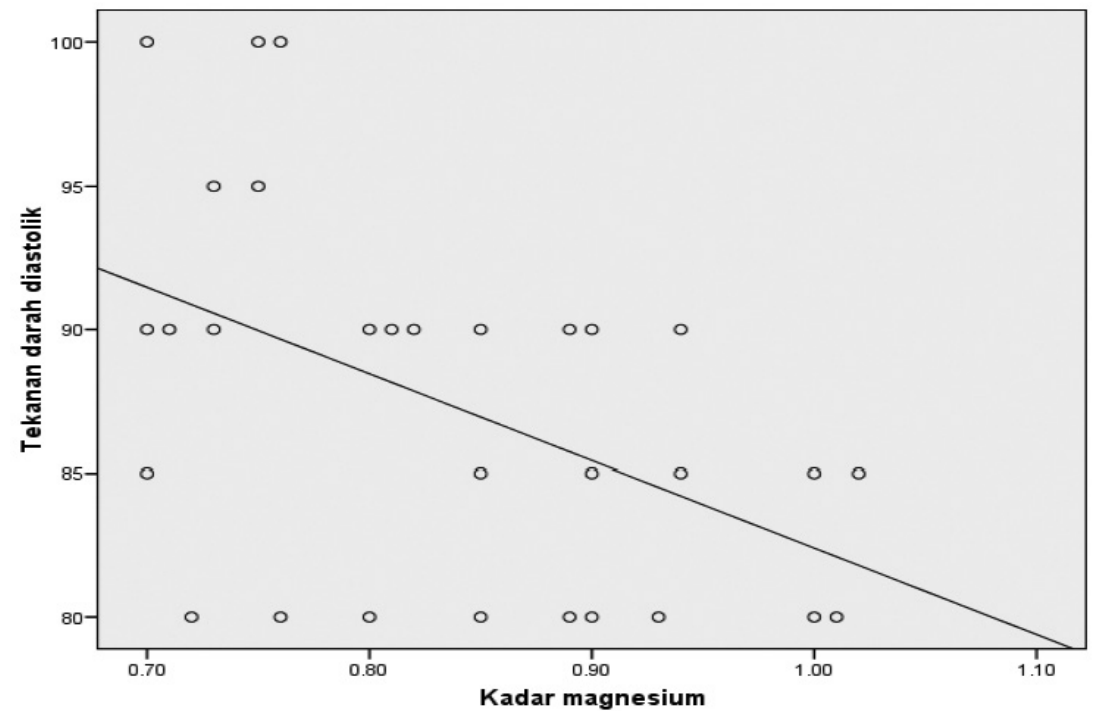

Figure 2. Scatter plot for correlation between blood serum Magnesium level and diastolic blood pressure

function of vascular smooth muscle cells and peripheral vascular resistance. The enzyme cofactor in the signal transduction pathway is involved in vascular contraction; magnesium can inhibit vasoconstriction induced by cytosolic accumulation of calcium concentrations. High extracellular magnesium levels are associated with improvements in hemodynamic status, such as blood flow, vascular resistance, and the function of the capacitance of blood vessels, which contribute to the pathology of hypertension. Besides magnesium shows antioxidant benefits in preventing hypertension by reducing damage to blood vessels from oxidative stress and preventing vascular damage. ${ }^{13,14,15}$

The predialysis excess fluids will increase vascular resistance and heart rate. Patients who are experiencing intradialytic hypertension have a significant increase in the peripheral vascular resistance at the end of the dialysis. In the presence of an increase in post-dialysis blood pressure, it reflects the subclinical excess volume. A relative decrease in the blood volume and total body volume resulting in the decreased blood flow to kidneys and stimulating the renin release which causes hypertension due to the conversion angiotensin I to angiotensin II, vasoconstriction and aldosterone secretion. ${ }^{10}$

The findings in this study are in accordance with Zhang et al. in 2016 findings from 34 randomized, double-blind, placebo-controlled trials that showed a significant antihypertensive effect of magnesium supplementation on systolic blood pressure among normotensive or hypertensive patients. ${ }^{5}$ Another study by Dickinson in 2006 also found that there was a decrease but not significant in a Cochrane review of 12 randomized controlled trials in hypertensive patients. ${ }^{16}$

The results showed that serum magnesium levels have a moderate inverse correlation with the diastolic blood pressure. The diastolic blood pressure is directly proportional to peripheral resistance. Peripheral resistance is the resistance of blood vessels against the bloodstream, which is influenced by viscosity and blood vessels. The vascular endothelial dysfunction can cause an increase in peripheral resistance. The Shina Lee et al. Study states that the increase in the serum magnesium levels is directly proportional to endothelial function. ${ }^{17}$ The limitation of this study is that it does not measure vascular endothelial function.

\section{CONCLUSIONS}

There is a strong negative correlation between the Magnesium serum level and the systolic blood pressure. While a moderate negative correlation between the Magnesium serum level and the diastolic blood pressure was observed in this study, a further research is needed to analyze the corresponding factors which are affecting the blood pressure.

\section{REFERENCES}

1. KDIGO. Clinical practice guideline for the evaluation and management of chronic kidney disease.2012, available from; http://www.kdigo.org

2. Henry Ford Health System. Chronic kidney disease: Clinical practice recommendations for 
primary care physicians and healthcare providers. Edition 6.0;2011, available from ; https://www.asn-online. org

3. Pusat Data dan Informasi Kementerian Kesehatan RI, Infodatin .2017:1-2

4. Perkumpulan Nefrologi Indonesia (PERNEFRI), 4th Report of Indonesian Renal registry. 2011:13

5. National kidney foundation, annual report. 2005. Available from; www.kidney.org

6. Biolab Medical Unit Nutritional and Environmental Medicine. Magnesium. 2013. Available from: www.biolab. co.uk

7. Toka HR, Al-Romaih $\mathrm{K}$ et al.: Deficiency of the calcium-sensing receptor in the kidney causes parathyroid hormone-independent hypocalciuria. J Am Soc Nephrol.2012;23:1879-1890

8. Mohammad Hassan Entezari. The effect of supplementary calcium on blood pressure in healthy adult women aged 1830 years in Tehran, Iran. J Educ Health Promot. 2015;4:67

9. Humphrey S, Kirby R, Rudloff E. Magnesium physiology and clinical Therapy in veterinary critical care. J Vet Emerg Crit Care.2015; 25(2):210-25

10. Manal Mohamed Zaher et al. Serum Magnesium Level and Vascular Stiffness in Children with Chronic Kidney Disease on Regular Hemodialysis. Saudi J Kidney Dis Transpl.2016;27(2):233-240

11. Muhammad Rafique Ansari et al. Correlation of Serum Magnesium with Dyslipidemia in Patients on Maintenance Hemodialysis. Saudi J Kidney Dis Transpl 2012;23(1):21-25
12. Salamanja et al. Hubungan lama menjalani hemodialisis dengan stress pada pasien penyakit ginjal kronik di RSUD Prof. Dr. H. Aloe Saboe Kota Gorontalo.2015;(3): 2-5

13. David A. Mccarron, Cynthia D. Morris, Richard Bukoski. The calcium paradox of essential hypertension. Division of Nephrology and Hypertension, Oregon Health Sciences University, Portland, Oregon, USA.. AJM. 2007;82(1 Supplement 2):27-33

14. Magnesium liquicolor. Photometric colorimetric test for Magnesium with Lipid Clearing Factor. 2010

15. Zhang Xi, et al. Effects of Magnesium Supplementation on Blood Pressure ; A Meta-Analysis of Randomized DoubleBlind Placebo-Controlled Trials. Hypertension. 2016;68:2030

16. Houston Mark, The Role of Magnesium in Hypertension and Cardiovascular Disease, J Clin Hypertens (Greenwich). 2011;13:843-47

17. Shina Lee et al. The Relationship between Magnesium and Endothelial Function in End-Stage Renal Disease Patients on Hemodialysis; Yonsei Med J.2015;57(6):1446-1453

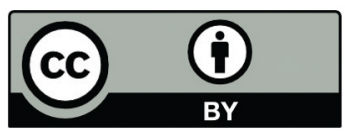

This work is licensed under a Creative Commons Attribution 